\title{
The Eating Motivation Survey: results from the USA, India and Germany
}

\author{
Gudrun Sproesser ${ }^{1, *}$, Matthew B Ruby ${ }^{2} \dagger$, Naomi Arbit ${ }^{3}$, Paul Rozin ${ }^{2}$, Harald T Schupp ${ }^{4}$ \\ and Britta Renner ${ }^{1}$ \\ 'University of Konstanz, Psychological Assessment and Health Psychology, Box 47, 78457 Konstanz, Germany: \\ ${ }^{2}$ University of Pennsylvania, Department of Psychology, Philadelphia, PA, USA: ${ }^{3}$ Columbia University, Department \\ of Nutrition, New York, NY, USA: ${ }^{4}$ University of Konstanz, General Psychology, Konstanz, Germany
}

Submitted 4 November 2016: Final revision received 1 August 2017: Accepted 22 August 2017: First published online 30 0ctober 2017

\begin{abstract}
Objective: Research has shown that there is a large variety of different motives underlying why people eat what they eat, which can be assessed with The Eating Motivation Survey (TEMS). The present study investigates the consistency and measurement invariance of the fifteen basic motives included in TEMS in countries with greatly differing eating environments.

Design: The fifteen-factor structure of TEMS (brief version: forty-six items) was tested in confirmatory factor analyses.

Setting: An online survey was conducted.

Subjects: US-American, Indian and German adults (total $N 749$ ) took part.

Results: Despite the complexity of the model, fit indices indicated a reasonable model fit (for the total sample: $\chi^{2} / \mathrm{df}=4.03$; standardized root-mean-squared residual $(\mathrm{SRMR})=0.063$; root-mean-square error of approximation $(\mathrm{RMSEA})=$ 0.064 (95\% CI 0.062, 0.066)). Only the comparative fit index (CFI) was below the recommended threshold (for the total sample: $\mathrm{CFI}=0 \cdot 84$ ). Altogether, 181 out of 184 item loadings were above the recommended threshold of $0 \cdot 30$. Furthermore, the factorial structure of TEMS was invariant across countries with respect to factor configuration and factor loadings (configural $v$. metric invariance model: $\Delta \mathrm{CFI}=$ $0.009 ; \Delta$ RMSEA $=0.001 ; \Delta S R M R=0 \cdot 001)$. Moreover, forty-three out of forty-six items showed invariant intercepts across countries.

Conclusions: The fifteen-factor structure of TEMS was, in general, confirmed across countries despite marked differences in eating environments. Moreover, latent means of fourteen out of fifteen motive factors can be compared across countries in future studies. This is a first step towards determining generalizability of the fifteen basic eating motives of TEMS across eating environments.
\end{abstract}

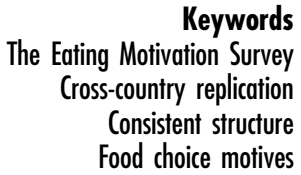

Most research across disciplines, including psychology, nutrition and public health, has focused on the pathology of eating, such as eating disorders and obesity. For example, the database ISI Web of Science yields more than 18000 entries for the topic 'eating disorder' but less than 500 entries for the topic 'normal eating'. While studying pathological eating behaviour is without doubt an important endeavour, this is by definition focusing mainly on the health-related aspects and consequences of eating behaviours. However, to get more insight on how to prevent people from starting to exhibit dysfunctional eating behaviours, a broader understanding of the aspects and functions of

$\dagger$ Current affiliation: La Trobe University, Department of Psychology and Public Health, Wodonga, VIC, Australia. non-pathological or 'normal' eating behaviour might be important. Specifically, understanding why we eat what we eat is crucial, as eating motives have also been found to be related to healthy eating behaviour ${ }^{(1-6)}$.

There is a large variety of different determinants and motives for why people eat what they eat, such as good taste, weight control or health reasons ${ }^{(7-9)}$. The first systematic attempt to assess the different motives for why people eat what they eat was in a scale developed by Steptoe et al. (the Food Choice Questionnaire (FCQ $)^{(8)}$; see also Konttinen et $\left.a l^{(10)}\right)$. However, given that important motives such as social or physiological motives were not included in the FCQ, The Eating Motivation Survey (TEMS) ${ }^{(11)}$ was developed, including a more extensive set of motives and a multifaceted procedure. Specifically, 331 reasons for why people eat what 
they eat were compiled from existing research and from interviews with nutritionists and expert discussions in Germany. Following approaches used in personality psychology $^{(12,13)}$ (see John and Srivastava ${ }^{(14)}$ for an overview), which use factor-analytical approaches to reduce large sets of personality descriptions to form a general taxonomy of personality traits based on a small number of 'basic' personality traits (i.e. the 'Big Five ${ }^{(15-18)}$ ), this large set of reasons for eating was reduced in factor analyses to fifteen 'basic' eating motives. These fifteen motives comprise eating particular foods and eating in general because of a good taste, habit, hunger, health concerns, convenience, pleasure, traditions, natural concerns, sociability, price considerations, the visual appeal of foods, weight control concerns, to regulate negative affect, and because of social norms and social image concerns (see Table 2 below for a fuller description of the motives).

The fifteen basic motives of TEMS have been consistently found across different groups within Germany. Specifically, Renner et $_{\text {al }}{ }^{(11)}$ showed that the factor structure of TEMS was generally invariant for women as compared with men, younger as compared with older people, and normal- as compared with overweight people. Hence, this speaks in favour of fifteen basic eating motives that are present to a greater or lesser degree across different groups. However, this does not mean that groups do not differ in the mean level of motives. In fact, large differences between groups occurred in the mean importance of motives. For instance, women had higher mean values than men on ten out of the fifteen motive scales. Yet, a comparable factor structure is a prerequisite for drawing comparisons of mean levels between groups ${ }^{(19)}$.

Finding consistency of TEMS structure across groups does not, however, address whether these motives also apply in different contexts. For instance, countries differ remarkably in their eating environments ${ }^{(20)}$ and in the way their populations think about food ${ }^{(21)}$. For instance, research has documented marked country differences not only in what people eat ${ }^{(22)}$ but also in food portion sizes ${ }^{(20)}$, variety preference $^{(23)}$, food-health associations ${ }^{(21)}$, and the importance of organic or convenience products ${ }^{(24)}$. These clear differences in eating environments between countries raise the question of whether there are also differences in the consistency of eating motives across countries; that is, whether the same factor structure can be applied in different countries. There is already some evidence on the consistency of selected eating motives of TEMS in two other countries. First, the Health motive was recently reliably assessed in a Chinese sample ${ }^{(25)}$. Second, Pechey et al. ${ }^{(26)}$ assessed the eating motives Liking, Habit, Need and Hunger, Health, Convenience, Pleasure, Price and Weight Control in a UK sample. However, until now, there has not been a systematic investigation of the replicability of the fifteen basic motives of TEMS across countries differing greatly in eating environments. Such an investigation might help to explain why certain countries differ in concern about diet, eating behaviour and diet-related diseases, and thus facilitate the generation of interventions to promote health.

\section{The present study}

The present study investigated whether the fifteen basic motives of TEMS can consistently be found across different countries and eating environments. Moreover, measurement invariance of TEMS was tested to determine whether mean comparisons across countries are valid. Criteria for the selection of countries for the study were diversity in terms of eating environment, cuisine and geography $^{(27)}$.

These criteria led to the selection of the USA as an example for a Western, industrialized country. The US-American eating environment has been found to be characterized by an emphasis on quantity rather than quality, and a high preference for variety and for comforts instead of joys ${ }^{(23)}$. Also, US-Americans associated food most with health and least with pleasure as compared with Europeans and the Japanese ${ }^{(21)}$.

As a second country, India was selected as an example for an Eastern, developing country, with the second highest population in the world, from the world's most populous continent. The Indian eating environment is characterized by a high percentage of vegetarians ${ }^{(28-30)}$. Moreover, the concepts of purity and pollution are intimately connected to food and eating, and the Indian eating environment is marked largely by norms regarding social order and hierarchy ${ }^{(28)}$.

Lastly, Germany was also included in the current study to directly compare findings from the USA and India with the country in which the fifteen basic motives were initially derived.

The comparability of the fifteen-factor structure of TEMS within the three countries was tested in confirmatory factor analyses.

\section{Methods}

\section{Procedure and sample}

Data were collected as part of an online survey study investigating psychological factors underlying eating behaviour $^{(31,32)}$. Convenience samples were recruited in all three countries. Specifically, in India and the USA, participants were recruited via Amazon's Mechanical Turk, a marketplace for online tasks ${ }^{(33)}$. Subscribers of Amazon's Mechanical Turk can earn some money by undertaking small online tasks. For the present study, they were invited to fill in the online survey and received \$US 2 for completing the questionnaire. As Amazon's Mechanical Turk did not provide a marketplace for Germans when the study was conducted, German participants were invited to the study through an email sent to several mailing lists; for example, of students and former study participants interested in further participation. In Germany, participants were free to forward the link to their acquaintances to recruit additional participants. As incentive for German participants, ten vouchers for Amazon, worth $10 €$ each, were awarded by lottery. 
In total, 887 participants took part in an online survey (Germany: $n$ 357; India: $n$ 326; USA: $n$ 204; Unipark survey software, Globalpark AG, Hürth, Germany). Out of these, 138 participants (16\%) filled out less than $75 \%$ of the survey, or failed two or more attention checks (see 'Measures' section below). These participants were excluded from analysis. Sample characteristics of the remaining 749 participants are displayed in Table 1. Women were over-represented in the German sample. As expected, BMI was highest in the US sample. Noticeably, the Indian sample had a higher average BMI than the Indian population $\left(20-21 \mathrm{~kg} / \mathrm{m}^{2}\right.$, depending on the social group $^{(34)}$ ) and rated their socio-economic status slightly higher than middle in their country. As $27.5 \%$ of Indians fall below the poverty line ${ }^{(35)}$, wealthy people are almost certainly over-represented in the Indian sample.

Comparing the study sample with the dropout sample showed no significant differences in terms of gender (54 v. 58\% female, $\chi^{2}(2)=1.82, P=0.402$ ). However, the study sample was slightly older $(35$ v. 32 years, $F(1,863)=4.35, \quad P=0.037)$, had a higher BMI (25 $v$. $\left.23 \mathrm{~kg} / \mathrm{m}^{2}, \quad F(1,827)=4.33, P=0.038\right)$ and lower socioeconomic status $(5.3$ v. 5.9, $F(1,861)=17 \cdot 00, P<0 \cdot 001)$ than the dropout sample.

\section{Ethics, consent and permissions}

The ethics board of the University of Konstanz approved the study protocol. The procedures were performed in compliance with relevant laws and institutional guidelines. We followed the German Psychological Society's (Deutsche Gesellschaft für Psychologie) guidelines for conducting psychological studies (see http://www.dgps. de/index.php?id = 96422; paragraph C.III). These are similar to those of the American Psychological Association. The study conforms to the Declaration of Helsinki. All participants consented to participate in the study by starting the online survey after being fully informed about the study.

\section{Measures}

\section{Demographics}

Participants were asked about their gender, age, height, weight and socio-economic status. To assess socio- economic status, a question was adapted from the Cantril ladder $^{(36)}$ where people are asked to rate where they stand in the society in their country from 1 (people with least money, education, and worst jobs) to 9 (people with most money, education, and best jobs).

\section{Eating motives}

German participants completed the German version of the brief TEMS ${ }^{(11)}$, and Indian and US-American participants completed the English version. After in-depth discussion with American-English native speakers about adequate translations of German items, wording of two English items of the original TEMS was changed slightly: (i) the original TEMS item 'because it is the most convenient' was changed to 'because it is convenient' (German: 'weil es wenig Aufwand bedeutet'); and (ii) similarly, the item 'because it is organic' was changed to 'because it stems from organic farming' (German: 'weil es aus biologischer Landwirtschaft stammt'). Moreover, the original TEMS item 'because it is natural (e.g. not genetically modified)' was split into the two items 'because it is natural' and 'because it is not genetically modified' because country differences in attitudes to genetic engineering have been found to be greater than country differences in attitudes to natural ${ }^{(37)}$. The forty-six items were preceded by the item stem 'I eat what I eat...' and answers were given on a 7-point rating scale from 1 'never' to 7 'always'.

\section{Attention checks}

To guarantee adequate data quality, three attention checks were included in the questionnaire ('I regularly eat rocks', 'I enjoy eating plastic' and 'I think that the Earth is a cube'). Participants who agreed with two or more of these questions were excluded from analyses.

As data were collected as part of larger study investigating psychological factors underlying eating behaviour, participants were also asked about their eating habits $(38,39)$ and eating concerns ${ }^{(21,40)}$, the meaning of food and eating for them ${ }^{(41)}$, concerns about global problems ${ }^{(31,42)}$, concerns about meat eating (MB Ruby, P Rozin, N Arbit et al., unpublished results), as well as filled out the Positive Eating scale ${ }^{(32)}$. These data are reported elsewhere ${ }^{(31,32)}$.

Table 1 Sociodemographic characteristics of the study sample and differences between countries

\begin{tabular}{|c|c|c|c|c|c|c|c|c|c|c|c|}
\hline & \multicolumn{2}{|c|}{$\begin{array}{l}\text { Pooled sample } \\
\qquad(N 749)\end{array}$} & \multicolumn{2}{|c|}{$\begin{array}{l}\text { Germany } \\
(n \text { 297) }\end{array}$} & \multicolumn{2}{|c|}{$\begin{array}{l}\text { India } \\
(n \text { 254) }\end{array}$} & \multicolumn{2}{|c|}{$\begin{array}{l}\text { USA } \\
(n \text { 198) }\end{array}$} & \multirow[b]{2}{*}{$x^{2}$ or $F$} & \multirow[b]{2}{*}{ df } & \multirow[b]{2}{*}{$P$} \\
\hline & $n$ or mean & $\%$ or SD & $n$ or mean & $\%$ or SD & $n$ or mean & $\%$ or SD & $n$ or mean & $\%$ or SD & & & \\
\hline Women, $n$ and $\%$ & 406 & 54 & 240 & 81 & 80 & 32 & 86 & 43 & 153 & 4 & $<0.001$ \\
\hline Men, $n$ and $\%$ & 341 & 46 & 55 & 19 & 174 & 68 & 112 & 57 & & & \\
\hline Age (years), mean and SD & 35 & $12 \cdot 5$ & 36 & $14 \cdot 8$ & 34 & $10 \cdot 3$ & 35 & $11 \cdot 1$ & $1 \cdot 11$ & 2,746 & 0.329 \\
\hline BMI $\left(\mathrm{kg} / \mathrm{m}^{2}\right)$, mean and SD & 24.7 & 5.5 & 23.7 & 4.7 & $24 \cdot 3$ & 4.8 & $26 \cdot 7$ & $6 \cdot 8$ & 19.45 & 2,728 & $<0.001$ \\
\hline SES, mean and SD & $5 \cdot 3$ & 1.4 & 5.9 & $1 \cdot 2$ & 5.5 & $1 \cdot 2$ & $4 \cdot 3$ & 1.3 & 96.74 & 2,746 & $<0.001$ \\
\hline
\end{tabular}

SES, socio-economic status.

SES was measured with a question adapted from the Cantril ladder ${ }^{(36)}$ where people are asked to rate where they stand in the society in their country from 1 (people with least money, education, and worst jobs) to 9 (people with most money, education, and best jobs). 


\section{Analytical procedure}

Statistical analyses were conducted using the statistical software package IBM SPSS Statistics and added module AMOS (versions 22 and 24 for Windows). Missing data in TEMS were imputed using the Expectation Maximization algorithm in IBM SPSS Statistics ${ }^{(43)}$. Missing values were below $5 \%$ for all imputed variables. Item distributions were inspected for multivariate normality. Skewness and excess of all items were below the thresholds of 2 and 7 , respectively, as suggested by Curran et al. ${ }^{(44)}$. Since items did not correlate above $0 \cdot 85$, no marked collinearity restrictions existed.

To investigate consistency of eating motives across countries, confirmatory factor analyses using maximum likelihood solutions were conducted. The item with the highest factor loading was fixed to 1.0 for each factor, respectively. Model fit was assessed by the comparative fit index (CFI), the standardized root-mean-squared residual (SRMR) and the root-mean-square error of approximation (RMSEA), as recommend by Kline ${ }^{(45)}$. CFI constitutes an incremental fit index which measures the proportionate improvement in fit by comparing the target model with a null model in which all observed variables are uncorrelated $^{(46)}$. In contrast, RMSEA and SRMR are absolute fit indices, comparing the target model with a saturated model that exactly reproduces the sample covariance matrix $^{(46)}$. A reasonable fit is indicated by a CFI $\geq 0.90$, an SRMR $\leq 0.10$ and an RMSEA $\leq 0.08^{(45)}$ (note that $\mathrm{Hu}$ and Bentler $^{(46)}$ suggest a CFI $\geq 0.95$, an $\mathrm{SRMR} \leq 0.08$ and an RMSEA $\leq 0.06$ for a good fit). Because the $\chi^{2}$ statistic is sample-size dependent, the $\chi^{2} / \mathrm{df}$ ratio was additionally calculated, with $\chi^{2}$ not larger than $2-5$ times the $\mathrm{df}$ indicating a good fit ${ }^{(47)}$.

To test measurement invariance of TEMS across countries, multi-group confirmatory factor analyses were conducted. Three models were estimated in a stepwise approach $^{(19,48)}$. First, the configural invariance model imposed an identical simple structure model on the data, assuming the same pattern of zero and non-zero loadings across all countries. Second, the metric invariance model constrained all factor loadings to be equal across countries. Third, the scalar invariance model constrained all factor loadings and item intercepts to be equal across countries. According to $\mathrm{Chen}^{(49)}$, metric invariance is indicated if $\triangle \mathrm{CFI}$ between the configural and metric invariance model is $<0.010, \Delta$ RMSEA is $<0.015$ and $\triangle$ SRMR is $<0 \cdot 030$. Moreover, scalar invariance is indicated if $\Delta$ CFI between the metric and scalar invariance model is $<0 \cdot 010, \Delta$ RMSEA is $<0 \cdot 015$ and $\triangle$ SRMR is $<0 \cdot 010$.

\section{Results}

\section{Consistency of eating motives across countries}

Means, SD, standardized factor loadings and corrected item-scale correlations of the forty-six items for the full sample and for the three countries are displayed in
Table 2. Model fit for the full sample and for the three countries with fifteen correlated factors is displayed in Table 3. Motive correlations for the full sample and internal consistencies for the full sample and for the three countries are listed in Table 4. Motive correlations for the three countries are displayed in the online supplementary material, Tables S1-S3.

All factor loadings within the three countries and the total sample were statistically significant, indicating convergent validity $(P<0 \cdot 001$; see Table 2$)$. Only three out of 184 items loadings were below the recommended level of $0 \cdot 30^{(45)}$ : 'because I need energy' and 'in order to reward myself' in the US sample; 'because I'm hungry' in the Indian sample. Motive correlations within the total sample ranged from $-0 \cdot 10$ (Hunger and Affect Regulation) to $0 \cdot 70$ (Social Image and Social Norms), indicating sufficient discriminant validity (cf. Table 4).

For the total sample, thirteen out of the fifteen factors showed good internal consistencies with values higher than 0.70 (Germany, $n$ 13; India $n$ 9; USA, $n$ 12; see Table 4). The lowest internal consistencies occurred for the scale Need and Hunger, with especially low corrected item-scale correlations in the Indian and US samples (Table 2). Moreover, the scale Pleasure had a low internal consistency, especially in the Indian sample, driven mainly by a low corrected item-scale correlation of the item 'because I enjoy it'.

As Table 3 shows, model fit within the three countries and for the total sample varied from moderate to good. The $\chi^{2}$ statistics were significant $(P<0 \cdot 001)$, indicating no exact fit of the model, which is to be expected considering the large sample sizes ${ }^{(45)}$. Despite the complexity of the model with fifteen factors and forty-six items, the $\chi^{2} / \mathrm{df}$ ratio indicated a good approximate model fit in all samples, as values were below $\chi^{2} / \mathrm{df}=5^{(47)}$. Also, the SRMR and RMSEA indicated a reasonable approximate model fit. Only in the Indian sample was the RMSEA slightly above the recommended $0 \cdot 08^{(45)}$. The CFI was below the recommended threshold of 0.90 in all but the German sample ${ }^{(45)}$. These differences in model fit as a function of the fit index can be explained by the kind of fit index. Specifically, the acceptable values of SRMR and RMSEA indicate a satisfactory fit in comparison to the best possible model, whereas the low CFI indicates suboptimal improvement compared with the worst model. Additionally, Heene et $a l .{ }^{(50)}$ indicated that the CFI needs to be interpreted with caution when sample sizes are below $n 500$.

\section{Measurement invariance of TEMS across countries}

Table 5 shows that the configural invariance model fitted the data well, which indicates that the same factor structure is valid across countries. Specifically, $\chi^{2} / \mathrm{df}$, SRMR and RMSEA indicated a reasonable model fit. Only the CFI was below the recommended threshold of 0.90 , which was to be expected regarding results from one-group confirmatory factor analyses (Table 3). Comparing the 
Table 2 Means, standard deviations, standardized factor loadings (a) and corrected item-scale correlations $\left(r_{i(t-i)}\right)$ for TEMS items in confirmatory factor analysis 


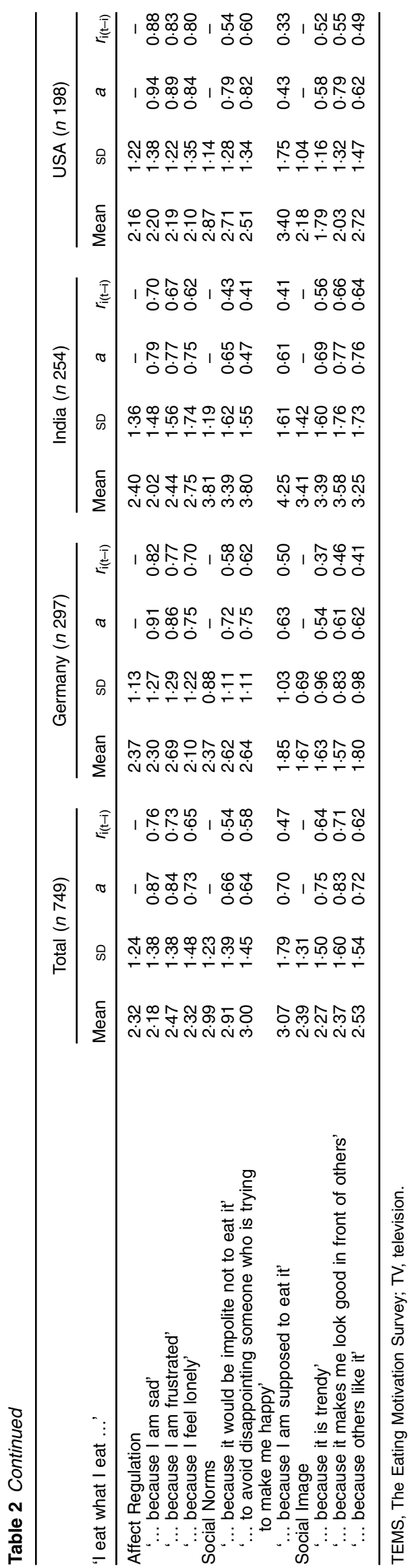

Table 3 Confirmatory factor analyses of TEMS items: goodness-offit indices for models for the full sample and for the three countries

\begin{tabular}{lccccccc}
\hline & $x^{2}$ & df & $x^{2} /$ df & CFI & SRMR & RMSEA & $90 \% \mathrm{Cl}$ \\
\hline Total & 3566 & 884 & 4.03 & 0.84 & 0.063 & 0.064 & $0.062,0.066$ \\
Germany & 1482 & 884 & 1.68 & 0.91 & 0.055 & 0.048 & $0.044,0.052$ \\
India & 2485 & 884 & 2.81 & 0.73 & 0.097 & 0.085 & $0.081,0.089$ \\
USA & 1711 & 884 & 1.94 & 0.83 & 0.087 & 0.069 & $0.064,0.074$
\end{tabular}

TEMS, The Eating Motivation Survey; CFI, comparative fit index; SRMR, standardized root-mean-squared residual; RMSEA, root-mean-square error of approximation.

All $X^{2}$ are significant at $P<0.001$.

configural and metric invariance model showed that the decrease in model fit was well within Chen's ${ }^{(50)}$ recommendations, indicating metric invariance $(\Delta \mathrm{CFI}=0.009$; $\triangle$ RMSEA $=0.001 ; \Delta$ SRMR $=0 \cdot 001)$. Hence, motive factors had the same meaning across countries ${ }^{(51)}$. Moreover, comparing the metric and scalar invariance model showed that the increases in RMSEA $(\triangle \mathrm{RMSEA}=0.008)$ and SRMR $(\triangle$ SRMR $=0 \cdot 007)$ were also well within Chen's ${ }^{(49)}$ recommendations, indicating scalar invariance. However, the decrease of the CFI was above the recommended level $(\Delta \mathrm{CFI}=0.092)$.

To determine the sources of this CFI decrease, separate models were estimated for each of the fifteen motive factors in a first step, as suggested by Cheung and Rensvold ${ }^{(52)}$. In each model, the intercepts of items within one factor were constrained to be equal across countries, whereas the remaining item intercepts were not. For each of these fifteen models, the decrease in the CFI in comparison to the metric invariance model was calculated, with a $\Delta \mathrm{CFI} \geq 0 \cdot 010$ indicating that item intercepts within this factor might be non-invariant. In a second step, items of all factors indicating non-invariant items were examined ${ }^{(52)}$. Specifically, for each of these items separate models were estimated in which that item's intercept was constrained to be equal across countries, whereas the other intercepts were not. As for factors, the CFI of each of these constrained models was compared with the CFI of the metric invariance model, with $\Delta \mathrm{CFI} \geq 0 \cdot 010$ indicating scalar non-invariance of this item.

Results showed that in eleven out of fifteen motive factors $\Delta$ CFI was smaller than 0.010. Only in four out of the fifteen motive factors was $\Delta$ CFI greater than or equal to $0 \cdot 010$, namely in the factors Social Image $(\Delta \mathrm{CFI}=$ 0.017), Social Norms $(\Delta \mathrm{CFI}=0.024)$, Visual Appeal $(\Delta \mathrm{CFI}=0 \cdot 010)$ and Natural Concerns $(\Delta \mathrm{CFI}=0 \cdot 010)$. An exploration of the thirteen items associated with these factors revealed that only three item intercepts were noninvariant: the intercepts of the items 'because it makes me look good in front of others' $(\Delta \mathrm{CFI}=0.012$; intercept for Germany $=1.57$, intercept for India $=3.58$, intercept for $\mathrm{USA}=2.03)$ and 'because it is trendy' $(\Delta \mathrm{CFI}=0.011$; intercept for Germany $=1.63$, intercept for India $=3.39$, intercept for USA $=1.79$ ) of the factor Social Image, as well as the intercept of the item 'because I am supposed to eat 
it' $(\Delta \mathrm{CFI}=0.021$; intercept for Germany $=1 \cdot 85$, intercept for India $=4 \cdot 25$, intercept for USA $=3.40$ ) of the factor Social Norms. Hence, the levels of the items were equal across countries for the factors Liking, Habits, Need and Hunger, Health, Convenience, Pleasure, Traditional Eating, Natural Concerns, Sociability, Price, Visual Appeal, Weight Control and Affect Regulation (scalar invariance). This implies that scores of these thirteen latent motive factors can be compared across countries. Moreover, as two out of three items of the motive factor Social Norms also showed scalar invariance, its latent means can also be compared across countries ${ }^{(51)}$. Only cross-country comparison on the motive factor Social Image should be treated with caution as two out of three items showed scalar non-invariance, meaning that samples from the three countries differ in their tendency to give higher or lower responses on the two items.

\section{Discussion}

The present study investigated whether the fifteen basic eating motives found to underlie eating behaviour in German samples also underlie eating behaviour in the USA and India. More precisely, it tested whether the fifteenfactor structure of TEMS is generalizable to people from the USA and India. Moreover, measurement invariance of TEMS across the three countries was investigated. Despite the complexity of the fifteen-factor model, the model fit indices $\chi^{2} / \mathrm{df}$, SRMR and RMSEA indicated a reasonable model fit with values below 5, 0.10 and 0.08 , respectively. Only the CFI was below the recommended threshold of 0.90. In total, 181 out of 184 item loadings were above the recommended threshold of 0.30 . Furthermore, the results indicated that the factorial structure of TEMS is invariant across countries with respect to factor configuration and factor loadings. Also, forty-three out of forty-six items had invariant intercepts across countries. Hence, eating motives were remarkably consistent in structure across countries despite marked differences in eating environments. Moreover, investigation of measurement invariance showed that latent means of fourteen out of fifteen motive factors can be compared across countries in future studies with representative samples. This is a first step towards determining consistency of the fifteen basic eating motives of TEMS across American, European and Asian countries.

In line with indications from previous research ${ }^{(25,26)}$, the eating motives Liking, Habits, Health, Convenience, Price and Weight Control appeared as consistent motives across countries. Moreover, the motives Traditional Eating, Natural Concern, Sociability, Visual Appeal, Affect Regulation, Social Norms and Social Image were found to be consistent across countries.

The cross-cultural validity of these eating motives is also in line with results regarding similar questionnaires. Specifically, the motives included in the FCQ (Health, 
Table 5 Confirmatory factor analyses of TEMS items: results from measurement invariance analysis

\begin{tabular}{lcccccrr}
\hline Model & $x^{2}$ & df & $x^{2} / \mathrm{df}$ & CFI & SRMR & RMSEA & $90 \%$ Cl \\
\hline Configural invariance & 5679 & 2652 & 2.14 & 0.822 & 0.055 & 0.039 & $0.038,0.041$ \\
Metric invariance & 5894 & 2714 & 2.17 & 0.813 & 0.056 & 0.040 & $0.038,0.041$ \\
Scalar invariance & 7558 & 2806 & 2.69 & 0.721 & 0.063 & 0.048 & $0.046,0.049$ \\
\hline
\end{tabular}

TEMS, The Eating Motivation Survey; CFI, comparative fit index; SRMR, standardized root-mean-squared residual; RMSEA, root-mean-square error of approximation.

All $X^{2}$ are significant at $P<0.001$.

Mood, Convenience, Sensory appeal, Natural content, Price, Weight control, Familiarity, Ethical concern $)^{(8)}$ have been found to be invariant across European samples and a South-East Asian sample ${ }^{(53,54)}$. In a similar vein, the Food-Related Lifestyles instrument, which includes similar constructs as TEMS (e.g. health concerns, price and convenience orientation) ${ }^{(55)}$, has been found to be invariant across European samples ${ }^{(56)}$. Also a long tradition of research on the Dutch Eating Behavior Questionnaire ${ }^{(57)}$ showed that its factors (emotional, restrained and external eating) are valid across a large range of European and Asian samples ${ }^{(58-60)}$.

It is, however, important to note that the scale Need and Hunger did not appear as a reliable scale in all countries. Similarly, reliability of the motive scale Need and Hunger has been low in previous work ${ }^{(11)}$. Despite its low reliability, though, it was one of the most important eating motives (see Table 2). This speaks in favour of taking hunger simply as hunger, as Jackson et al. ${ }^{(61)}$ put it, and thus as a unique, mono-faceted motive that is better captured with one item than with classical psychometric scales. Moreover, slight country differences were observed for the scale Pleasure. Specifically, loadings and item-scale correlations were higher in the German sample than in the other samples. Examining the correlations between the three items showed that in the German sample, all item correlations were acceptable. However, whereas correlations between the items in order to reward myself' and 'in order to indulge myself' were also acceptable in the US and Indian sample, the item 'because I enjoy it' correlated only weakly with the other two items both in the US and Indian sample. This might hint to a different meaning of the English item 'because I enjoy it' compared with the German item ('um es mir gut gehen zu lassen'), indicating an item bias ${ }^{(62)}$. Specifically, the English wording might tap more into the liking of food than into eating because of positive emotions. Hence, it is recommended that future research tests English wordings whose meaning is more similar to eating because of positive emotions.

We found that the factor configuration, factor loadings, and forty-three out of forty-six item intercepts were comparable across countries, which implies that latent means of fourteen out of fifteen motive factors can be compared across countries in future studies with representative samples ${ }^{(51)}$. Intercepts of the items 'because it makes me look good in front of others' (factor Social Image), 'because it is trendy' (factor Social Image) and 'because I am supposed to eat it' (factor Social Norms) were not comparable. This means that sample-specific response biases exist that are caused by other influences than variations in the underlying factor ${ }^{(56)}$. In other words, samples from the three countries differ in their tendency to give higher or lower responses on these items ${ }^{(51)}$. This does not prevent comparison of latent means across countries for the factor Social Norms because two of its items had invariant intercepts and loadings ${ }^{(51)}$. However, for the factor Social Image the raw data would need to be corrected for the bias before comparing the means across countries ${ }^{(56)}$.

Concerning interrelationships between motives, we replicated earlier findings ${ }^{(8,11,61)}$. Specifically, in our multicountry sample, high correlations were observed between the motives Sociability, Social Norms, Social Image, Visual Appeal, Traditional Eating and Habits. This close network of sociocultural and biological motives stood against health concerns, which only showed high correlations with Natural Content and Weight Control (see also Keller and van der Horst $\left.{ }^{(63)}\right)$. Hence, health campaigns that only target health concerns regarding eating might have difficulties in attaining sustainable eating behaviour changes in the different countries if they do not also address these sociocultural and biological motives ${ }^{(11)}$.

\section{Limitations}

There are some limitations to the present study. First of all, the fact that Indian participants filled in the English version of TEMS might have resulted in some noise in the data due to imperfect understanding of questions. Although we included attention (and understanding) checks in the questionnaire, imperfect understanding of some wording might explain why correlations in the Indian sample tended to be lowest. Second, our samples were not representative, oversampling, for example, wealthy Indians with English skills and access to the Internet. The lack of representativeness in terms of gender and BMI is unlikely to have affected the results, as the factor structure of TEMS has been shown to be invariant across gender and $\mathrm{BMI}^{(11)}$. Moreover, whereas comparing mean eating motives between countries would have been biased by systematic sample differences, the performed within-country correlations are not biased by such differences ${ }^{(64)}$. Still, future research is 
needed to address these limitations, translating TEMS into more languages and using representative samples.

\section{Conclusion and future research}

The present study is a first step towards a systematic investigation of the consistency of the fifteen basic eating motives across different eating environments. With regard to the consistency across three diverse samples of Germans, Indians and US-Americans, we can conclude that the conceptual organization of reasons why people eat is highly comparable between these groups. With this in mind, we can generalize the description of what drives normal eating behaviour in these countries and target ways to promote normal and healthy eating behaviour in order to help prevent diet-related diseases. Specifically, the multifaceted nature of normal eating behaviour implies that eating behaviour should not be reduced to single eating motives, such as health or weight control concerns, which are often targeted in public health campaigns. In light of the multifunctionality of normal eating behaviour, interventions that target single motives might not only be less effective but might even contribute to 'conflicted' eating behaviour. For instance, interventions targeting weight control may conflict with the motive for pleasure and eating enjoyment ${ }^{(65)}$, which might in turn pave the way to disordered eating. Future studies need to continue this line of research in other eating environments and include questions about eating motives that might not be included in TEMS yet because of uncommonness in Western countries to fully determine the basic motives for human eating behaviour.

\section{Acknowledgements}

Acknowledgements: The authors would like to thank Fee Benz and Juliane Müller for their support. Financial support: This research was supported by a fund from the Zukunftskolleg of the University of Konstanz within the second funding period of the Excellence Initiative of the German Federal Governments. The funding source had no role in the design/conduct of the study, collection/ analysis/interpretation of the data or preparation/review/ approval of the manuscript. Conflict of interest: None. Authorship: All authors contributed to the development of the study concept. G.S. and M.B.R. collected the data. G.S. conducted data analyses and B.R. contributed significantly to the interpretation of data. G.S. prepared the first manuscript draft and all other authors provided critical revisions. All authors approved the final version of the manuscript for submission and agreed to be accountable for all aspects of the work. Ethics of human subject participation: This study was conducted according to the guidelines laid down in the Declaration of Helsinki and all procedures involving human subjects/patients were approved by the ethics committee of the University of Konstanz. All participants consented to participate in this study by starting the online survey after being fully informed about the study.

\section{Supplementary material}

To view supplementary material for this article, please visit https://doi.org/10.1017/S1368980017002798

\section{References}

1. Eertmans A, Victoir A, Vansant G et al. (2005) Food-related personality traits, food choice motives and food intake: mediator and moderator relationships. Food Qual Prefer 16, $714-726$.

2. Glanz K, Basil M, Maibach E et al. (1998) Why Americans eat what they do. J Am Diet Assoc 98, 1118-1126.

3. Pollard TM, Steptoe A \& Wardle J (1998) Motives underlying healthy eating: using the Food Choice Questionnaire to explain variation in dietary intake. J Biosoc Sci 30, 165-179.

4. Sproesser G, Strohbach S, Schupp HT et al. (2011) Candy or apple? How self-control resources and motives impact dietary healthiness in women. Appetite 56, 784-787.

5. Steptoe A \& Wardle J (1999) Motivational factors as mediators of socioeconomic variations in dietary intake patterns. Psychol Health 14, 391-402.

6. Sun YH (2008) Health concern, food choice motives, and attitudes toward healthy eating: the mediating role of food choice motives. Appetite 51, 42-49.

7. Ogden J, Oikonomou E \& Alemany G (2017) Distraction, restrained eating and disinhibition: an experimental study of food intake and the impact of 'eating on the go'. J Health Psychol 22, 39-50.

8. Steptoe A, Pollard TM \& Wardle J (1995) Development of a measure of the motives underlying the selection of food: the food choice questionnaire. Appetite 25, 267-284.

9. Bucher T \& Keller C (2015) The web-buffet - development and validation of an online tool to measure food choice. Public Health Nutr 18, 1950-1959.

10. Konttinen H, Sarlio-Lähteenkorva S, Silventoinen K et al. (2013) Socio-economic disparities in the consumption of vegetables, fruit and energy-dense foods: the role of motive priorities. Public Health Nutr 16, 873-882.

11. Renner B, Sproesser G, Strohbach S et al. (2012) Why we eat what we eat. The Eating Motivation Survey (TEMS). Appetite 59, 117-128.

12. Cattell RB (1943) The description of personality: basic traits resolved into clusters. J Abnorm Soc Psychol 38, 476-506.

13. Eysenck HJ \& SBG Eysenck (editors) (1969) Personality Structure and Measurement, 1st ed. London: Routledge \& Kegan Paul.

14. John OP \& Srivastava S (1999) The Big Five trait taxonomy: history, measurement, and theoretical perspectives. In Handbook of Personality: Theory and Research, 2nd ed., pp. 102-138 [AL Pervin and OP John, editors]. New York: Guilford Press.

15. Allport GW \& Odbert HS (1936) Trait names: a psycholexical study. Psychol Monogr 47, 1.

16. Goldberg LR (1990) An alternative 'description of personality': the big-five factor structure. J Pers Soc Psychol 59, 1216-1229. 
17. Norman WT (1967) 2800 Personality Trait Descriptors: Normative Operating Characteristics for a University Population. Ann Arbor, MI: University of Michigan.

18. Eysenck HJ (1991) Dimensions of personality: 16, 5 or 3? - Criteria for a taxonomic paradigm. Pers Individ Dif 12, 773-790.

19. Milfont TL \& Fischer R (2010) Testing measurement invariance across groups: applications in cross-cultural research. Int J Psychol Res 3, 111-121.

20. Rozin P, Kabnick K, Pete E et al. (2003) The ecology of eating: smaller portion sizes in France than in the United States help explain the French paradox. Psychol Sci $\mathbf{1 4}$ 450-454.

21. Rozin P, Fischler C, Imada S et al. (1999) Attitudes to food and the role of food in life in the USA, Japan, Flemish Belgium and France: possible implications for the diethealth debate. Appetite 33, 163-180.

22. Food and Agriculture Organization of the United Nations (2014) Food and nutrition in numbers. http://www.fao.org/ 3/a-i4175e.pdf (accessed June 2017).

23. Rozin P, Remick AK \& Fischler C (2011) Broad themes of difference between French and Americans in attitudes to food and other life domains: personal versus communal values, quantity versus quality, and comforts versus joys. Front Psychol 2, 177.

24. Pérez-Cueto FJA, Verbeke W, de Barcellos MD et al. (2010) Food-related lifestyles and their association to obesity in five European countries. Appetite 54, 156-162.

25. Siegrist M, Shi J, Giusto A et al. (2015) Worlds apart. Consumer acceptance of functional foods and beverages in Germany and China. Appetite 92, 87-93.

26. Pechey R, Monsivais P, Ng Y-L et al. (2015) Why don't poor men eat fruit? Socioeconomic differences in motivations for fruit consumption. Appetite 84, 271-279.

27. Norenzayan A \& Heine SJ (2005) Psychological universals: what are they and how can we know? Psychol Bull 131, 763-784.

28. Nagla M (2007) Feeding the family in India: an approach to household food consumption. Int J Consum Stud 31, 295-302.

29. Ruby MB (2012) Vegetarianism. A blossoming field of study. Appetite 58, 141-150.

30. Ruby MB, Heine SJ, Kamble S et al. (2013) Compassion and contamination. Cultural differences in vegetarianism. Appetite 71, 340-348.

31. Arbit N, Ruby MB, Sproesser G et al. (2017) Spheres of moral concern, moral engagement, and food choice in the USA, India and Germany. Food Qual Prefer 62, 38-45.

32. Sproesser G, Klusmann V, Ruby MB et al. (2017) The Positive Eating Scale: relationship with objective health parameters and validity in Germany, the USA, and India. Psychol Health (Epublication ahead of print version).

33. Buhrmester M, Kwang T \& Gosling SD (2011) Amazon's Mechanical Turk: a new source of inexpensive, yet highquality, data? Perspect Psychol Sci 6, 3-5.

34. Government of India (2015) Health and nutrition indicators by social groups. https://data.gov.in/catalog/healthand-nutrition-indicators-social-groups (accessed November 2016).

35. Government of India (2011) Selected socio-economic statistics, India. http://mospi.nic.in/mospi_new/upload/ sel_socio_eco_stats_ind_2001_28oct11.pdf (accessed March 2016).

36. Cantril H (editor) (1965) The Pattern of Human Concern, 2nd ed. New Brunswick, NJ: Rutgers University Press.

37. Rozin P, Fischler C \& Shields-Argelès C (2012) European and American perspectives on the meaning of natural. Appetite 59, 448-455.

38. National Health and Nutrition Examination Survey (2017) Dietary Screener Questionnaire. http://appliedresearch. cancer.gov/nhanes/dietscreen/dsq_english.pdf (accessed June 2017).

39. Sproesser G, Schupp HT \& Renner B (2014) The bright side of stress-induced eating: eating more when stressed but less when pleased. Psychol Sci 25, 58-65.

40. Rozin P, Bauer R \& Catanese D (2003) Food and life, pleasure and worry, among American college students: gender differences and regional similarities. J Pers Soc Psychol 85, 132-141.

41. Arbit N, Ruby MB \& Rozin P (2017) Development and validation of the Meaning of Food in Life Questionnaire (MFLQ): evidence for a new construct to explain eating behavior. Appetite 59, 35-45.

42. Schultz PW (2001) The structure of environmental concern concern for self, other people and the biosphere. J Environ Psychol 21, 327-339.

43. Gold MS \& Bentler PM (2000) Treatments of missing data: a Monte Carlo comparison of RBHDI, iterative stochastic regression imputation, and expectation-maximization. Struct Equ Modeling 7, 319-355.

44. Curran PJ, West SG \& Finch JF (1996) The robustness of test statistics to nonnormality and specification error in confirmatory factor analysis. Psychol Methods 1, 16-29.

45. Kline RB (editor) (2011) Principles and Practice of Structural Equation Modeling, 3rd ed. New York: Guilford Press.

46. Hu L-T \& Bentler PM (1999) Cutoff criteria for fit indexes in covariance structure analysis: conventional criteria versus new alternatives. Struct Equ Modeling 6, 1-55.

47. Bollen KA \& Long JS (editors) (1993) Testing Structural Equation Models. SAGE Focus Editions vol. 154. Thousand Oaks, CA: SAGE Publications, Inc.

48. Steenkamp J-BEM \& Baumgartner H (1998) Assessing measurement invariance in cross-national consumer research. J Consum Res 25, 78-107.

49. Chen FF (2007) Sensitivity of goodness of fit indexes to lack of measurement invariance. Struct Equ Modeling 14, 464-504.

50. Heene M, Hilbert S, Draxler C et al. (2011) Masking misfit in confirmatory factor analysis by increasing unique variances: a cautionary note on the usefulness of cutoff values of fit indices. Psychol Methods 16, 319-336.

51. van de Schoot R, Lugtig P \& Hox J (2012) A checklist for testing measurement invariance. Eur J Dev Psychol 9, 486-492.

52. Cheung GW \& Rensvold RB (1999) Testing factorial invariance across groups: a reconceptualization and proposed new method. J Manage 25, 1-27.

53. Januszewska R, Pieniak Z \& Verbeke W (2011) Food choice questionnaire revisited in four countries. Does it still measure the same? Appetite 57, 94-98.

54. Pieniak Z, Verbeke W, Vanhonacker F et al. (2009) Association between traditional food consumption and motives for food choice in six European countries. Appetite 53, 101-108.

55. Brunsø K \& Grunert KG (1995) Development and testing of a cross-culturally valid instrument: food-related life style. Adv Consum Res 22, 475-480.

56. Scholderer J, Grunert KG \& Brunsø K (2005) A procedure for eliminating additive bias from cross-cultural survey data. I Bus Res 58, 72-78.

57. van Strien T, Frijters JER, Bergers GPA et al. (1986) The Dutch Eating Behavior Questionnaire (DEBQ) for assessment of restrained, emotional, and external eating behavior. Int J Eat Disord 5, 295-315.

58. Wu S, Cai T \& Luo X (2017) Validation of the Dutch Eating Behavior Questionnaire (DEBQ) in a sample of Chinese adolescents. Psychol Health Med 22, 282-288.

59. Nagl M, Hilbert A, de Zwaan M et al. (2016) The German version of the Dutch eating behavior questionnaire: 
psychometric properties, measurement invariance, and population-based norms. PLoS One 11, e0162520.

60. Dakanalis A, Zanetti MA, Clerici M et al. (2013) Italian version of the Dutch Eating Behavior Questionnaire. Psychometric proprieties and measurement invariance across sex, BMI-status and age. Appetite 71, 187-195.

61. Jackson B, Cooper ML, Mintz L et al. (2003) Motivations to eat: scale development and validation. J Res Pers 37, 297-318.

62. van de Vijver FJR (2003) Bias and equivalence: crosscultural perspectives. In Cross-Cultural Survey Methods, 1st ed., pp. 143-155 [JA Harkness, FJR Van de Vijver and PP Mohler, editors]. Hoboken, NJ: John Wiley \& Sons.

63. Keller C \& van der Horst K (2013) Dietary restraint, ambivalence toward eating, and the valence and content of spontaneous associations with eating. Appetite 62, 150-159.

64. Heine SJ (editor) (2008) Cultural Psychology, 1st ed. New York: WW Norton \& Company.

65. Stroebe W, Mensink W, Aarts H et al. (2008) Why dieters fail: testing the goal conflict model of eating. $J$ Exp Soc Psychol 44, 26-36. 